\title{
Polylactide pins can effectively fix severely comminuted and unsalvageable radial head fracture: a retrospective study of $\mathbf{4 0}$ patients
}

\section{Liang Guo}

the 4th affliated hospital and university-town hospital of chongqing medical university

讴 li ( $\square$ jedimasterli@163.com )

the 4th affiliated hospital and university-town hospital of chongqing medical university https://orcid.org/0000-0003-0718-7536

\section{Xuhui Yang}

the 4th affiliated hospital and university-town hospital of chongqing medical university

Chao Yu

the 4th affiliated hospital and university-town hospital of chongqing medical university

Fei Gui

the 4th affiliated hospital and university-town hospital of chongqing medical university

\section{Research article}

Keywords: Polylactide pins, radial head fracture

Posted Date: January 21st, 2020

DOl: https://doi.org/10.21203/rs.2.21423/v1

License: (9) This work is licensed under a Creative Commons Attribution 4.0 International License. Read Full License

Version of Record: A version of this preprint was published at Injury on October 1st, 2020. See the published version at https://doi.org/10.1016/j.injury.2020.07.041. 


\section{Abstract}

Background The treatment of comminuted unsalvageable radial head fracture remains controversial. Open reduction and internal fixation are hard to achieve. Common techniques include radial head resection and arthroplasty. Both methods have characteristic complications. The present study aims to demonstrate the feasibility of treating unreducible radial head fractures with absorbable polylactide pins.

Methods A total of 17 patients with severely comminuted Mason type III radial head fractures were treated with open reduction and internal fixation using polylactide pins and 23 with metallic implants. Patients receiving both modalities were followed-up for a mean of 15 months (standard deviation [SD]: 2.6). Radiographic analysis was conducted 2, 30, 60 and 120 days after surgery. Measurements of range of motion (ROM), disability of arm shoulder and hands, Mayo elbow performance score and Broberg and Morrey elbow score were recorded, with treatments compared using a Mann-Whitney U test.

Result All fractures healed successfully. The data shows no statistical difference between the polylactide and metallic implant groups. Complications were infrequent and did not cause disability. All patients were satisfied with the surgical outcomes.

Conclusion Polylactide pins can feasibly treat severely comminuted radial head fractures which are normally considered unreducible. The outcomes were similar to those of metallic implants. This technique provides an optional treatment plan in addition to resection and arthroplasty, especially for young patients that refuse that form of treatment.

\section{Introduction}

Mason type $\mathbb{Q}-\mathbb{Q}$ radial head fractures in which the head is severely comminuted are considered unsalvageable and difficult to treat with open reduction and internal fixation (ORIF)(1). Such fractures have been previously treated with radial head resection with good results having been reported (2). However, long-term studies have demonstrated that radial head resection leads to a series of complications such as proximal migration of the radius, valgus instability and distal radioulnar joint (DRUJ) dysfunction $(3,4)$. So radial head arthroplasty has become the most popular treatment for such fractures. A wide variety of prostheses is available that is effective in preventing proximal migration of the radius which can increase dynamic stability of the elbow joint and $\operatorname{DRUJ}(5,6)$. Although radial head arthroplasty results in favorable outcomes, a number of mid to long-term retrospective studies have demonstrated that a considerable proportion of patients who undergo arthroplasty ultimately experience complications such as capitellum erosion, elbow joint arthrosis and loosening of the prosthesis (7-9). Although the majority of these patients are asymptomatic, there remains controversy as to whether arthroplasty should be performed on young patients.

With the development of absorbable fixation devices, the risk of joint obstruction and soft tissue irritation caused by implant loosening is eliminated, as the fixation device absorbs within 12 months. It is possible 
to use smaller, absorbable pins that are not threaded to fix intraarticular comminuted fractures, which are difficult to fix with metallic screws or plates.

The aim of the present study was to ascertain whether ORIF of unsalvageable radial head fractures using absorbable polylactide pins is practicable in comparison to treatment with traditional metallic plates and screws.

\section{Methods}

From May 2011 to April 2018, 103 patients with radial head fractures received surgical treatment in the department of orthopedic of University-town Hospital of Chongqing Medical University and was followed up for at least 12 months. Twenty patients underwent internal fixation with absorbable polylactide pins. The remaining patients were treated with traditional metallic fixation devices, namely headless screws and plates. The inclusion criteria required patients to have a Mason type $₫$ radial head fracture, with a radial head comminuted into more than 3 fragments. In order to eliminate the influence of soft tissue damage, patients whose fracture was combined with elbow joint dislocation, complete ligament rupture,

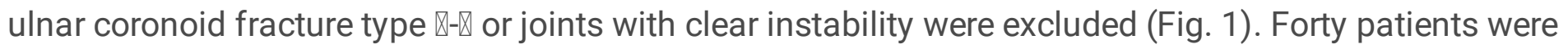
eligible for inclusion, of which 17 were fixed with absorbable polylactide pins and 23 treated with metallic plates and headless screws. Patients treated with polylactide pins were defined as the experimental group, the others as the control. The mean number of fragments in the experimental group was 4 (SD: 0.6) with 3 in the control group (SD: 0.3) (Fig. 3). Patients were followed-up for a mean of 14.7 months (SD: 2.6). Twenty eight patients were women and 12 were men, mean age 42.3 years (SD: 11.0), 17 of whom were under 40 years of age. Nineteen fractures were on the right side, all being right-handed and 21 were on the left side.

All surgery was performed by skilled surgical teams. A lateral approach was used to access the radial head. Fractures of the experimental group were fixed with $1.5 \mathrm{~mm}$ degradable pins fabricated from Llactic acid, D-lactic acid and trimethylene carbonate (Inion OTPS ${ }^{\mathrm{Tm}}$ Pin System, Inion, Finland). The reduction process occasionally required the use of an on-table reconstruction technique to reduce the comminuted radial head in vitro (Fig. 2). The radial head was temporarily fixed with at least four $1.0 \mathrm{~mm}$ kirschner wires in multiple orientations which were replaced one by one using degradable pins whose lengths were modified. The reconstructed radial head was then reattached to the shaft and fixed with at least 3-4 degradable pins in a cross orientation. Conversely, the control group was fixed with $2.0 \mathrm{~mm}$ conventional low-profile mini T plates (Weigo mini low-profile plate system, Weigo, China) and $2.5 \mathrm{~mm}$ VPS headless compression screws (Weigo VPS headless compression screw, Weigo, China). Each plate was placed on a non-articulating region of the radial head (10) and VPS screws sunken below the cartilage to prevent any interference with rotation. Flexion, extension and rotation of the elbow joint were checked to ensure there was no obstruction. A lateral stress test was performed to ensure no lateral instability prior to repair of the annular ligament, after which the incision was routinely closed. 
Following surgery, a hinged elbow joint brace was utilized in order to reduce edema and pain. The hinge was unlocked to allow passive flexion and extension exercises several times a day after pain was relieved. Progressive weight bearing was initiated after early healing of the fracture was confirmed in radiological follow-up. Metallic implants were removed 46 weeks (SD: 8) after surgery, depending on the demands of each patient.

Patients were evaluated at every follow-up, in which the Mayo Elbow Performance Index (MEPI), Broberg and Morrey elbow score, visual analogue scale (VAS) score of pain during elbow joint movement and Disabilities of the Arm, Shoulder and Hand (DASH) outcome measure were recorded. Radiographic assessment was conducted at each follow-up until fracture was completely healed or the implant removed.

\section{Statistical analysis}

Following the collection of the final follow-up data, a Mann-Whitney $U$ test was conducted using SPSS 20.0 (IBM, USA) to assess the statistical significance of differences between the two types of implant. A p value less than 0.05 was considered significant.

\section{Results}

Each fracture was clinically healed by the final follow-up examination (June 2019). No patient suffered nonunion and no reoperation was required. The duration of surgery for the experimental group was $134 \mathrm{~min}$ (SD: $21 \mathrm{~min}$ ), and $131 \mathrm{~min}$ (SD: $19 \mathrm{~min}$ ) for the control group, which was not significantly different. Blood loss during surgery was $121 \mathrm{ml}$ (SD: $25 \mathrm{ml}$ ) to $124 \mathrm{ml}$ (SD: $27 \mathrm{ml}$ ) for the experimental and control groups respectively, also not significantly different (Fig. 3).

Four of the patients in the experimental group and 5 in the control group experienced mild pain at the maximum extent of range of motion (VAS 1-2). Only one considered that the pain affected his daily activities.

The MEPI scores of the two groups are presented in Table 1. A greater number of patients with metallic implants scored "excellent" than the experimental group, but the only patient to score "fair" was also in the control group, complaining of mild pain during a change in the weather and requiring non-steroidal anti-inflammatory drugs (NSAIDs) to ease the pain. However, there was no statistical difference in MEPI scores between the two groups. The Broberg and Morrey scores (Table 2) were consistent with those of the MEPI, and were also not significantly different between the two groups. Range of motion values are displayed in (Table 3 ) and also are not statistically different between the two groups. Range of extension deficit is common, but the majority of the deficit is less than $30^{\circ}$. The deficit in only 8 patients was greater than $30^{\circ}, 4$ fixed with absorbable pins and 4 with metallic implants. The range of motion from full extension to flexion was greater than $100^{\circ}$, and pronation to supination more than $50^{\circ}$. DASH outcome measures represent upper limb function in daily activities. The mean score in the experimental group was 4.5 (SD: 3.0), compared with 3.7 (SD: 3.5) for the control group, a difference that was not significantly 
different $(p=0.5)$. No patient score was higher than 10 and no one complained about experiencing disability sufficiently severe to affect the activities of daily life.

Table 1

the MEPI score

\begin{tabular}{|c|c|c|c|c|c|c|}
\hline \multirow[t]{2}{*}{ Fixation type } & \multirow{2}{*}{$\begin{array}{l}\text { MEPI score, } \\
\text { Mean (SD) }\end{array}$} & \multirow[t]{2}{*}{$\mathrm{p}$} & \multicolumn{4}{|c|}{ Number of patients } \\
\hline & & & Excellent,n(\%) & Good,n(\%) & Fair,n(\%) & Poor,n(\%) \\
\hline Polylactide pin & $91(\mathrm{SD} 7)$ & 0.4 & $9(53 \%)$ & $8(47 \%)$ & 0 & 0 \\
\hline Metallic implant & 94(SD 9) & & $17(74 \%)$ & $5(22 \%)$ & $1(4 \%)$ & 0 \\
\hline
\end{tabular}

Table 2

broberg and morrey score

\begin{tabular}{|c|c|c|c|c|c|c|}
\hline \multirow[t]{2}{*}{ Fixation type } & \multirow{2}{*}{$\begin{array}{l}\text { Elbow score, } \\
\text { Mean (SD) }\end{array}$} & \multirow[t]{2}{*}{$\mathrm{p}$} & \multicolumn{4}{|c|}{ Number of patients } \\
\hline & & & Excellent,n(\%) & Good,n(\%) & Fair,n(\%) & Poor,n(\%) \\
\hline Polylactide pin & 93(SD 3) & \multirow[t]{2}{*}{0.7} & $6(35 \%)$ & $11(65 \%)$ & 0 & 0 \\
\hline Metallic implant & 93(SD 5) & & $10(44 \%)$ & $12(52 \%)$ & $1(4 \%)$ & 0 \\
\hline
\end{tabular}

Table 3

motion range

\begin{tabular}{|llll|}
\hline & $\begin{array}{l}\text { Absorbable rods, } \\
\text { Mean (SD) }\end{array}$ & $\begin{array}{l}\text { Metallic implant, } \\
\text { Mean (SD) }\end{array}$ & $\mathbf{p}$ \\
\hline flexion & 134(SD 7) & 135(SD 8) & 0.6 \\
\hline Extension deficit & $21($ SD 9) & 20(SD 8) & 0.9 \\
\hline pronation & $67($ SD 6) & $63($ SD 9) & 0.08 \\
\hline supination & 72(SD 5) & 73(SD 8) & 0.8 \\
\hline
\end{tabular}

One patient who received an absorbable pin fixation experienced signs of fracture displacement during radiological follow-up 1 month after surgery (Fig. 4). However, due to pain and swelling 2 days after surgery, radiographic images were acquired in a slightly pronated position in which a possible malreduction was obscured. Therefore, it is not possible to determine whether the displacement was due to fixation failure or malreduction. The fracture suffered a delayed union but was fully healed 6 months after surgery. The radial head exhibited mild bone resorption and the articular space between radial head and capitellum had broadened slightly. But there was no evidence of lateral instability. The patient only complained about mild pain when the weather changed and occasionally required NSAIDs to ease the pain. Daily activities were not affected and the patient was satisfied with the outcome. 
One patient who received absorbable pin fixation reported wrist pain during early active-assisted exercise 4 days after surgery. An additional Essex-Lopresti lesion had been missed prior to surgery due to plaster splint immobilization and pain from the elbow joint restricting pronation and supination of the forearm. A hinged elbow joint brace was utilized for an additional 3 weeks. At the final follow-up ( 14 months after surgery), the patient's functional score was "good", with $30^{\circ}$ of extension deficit, but range of motion from full extension to flexion was $100^{\circ}$ and from pronation to supination $130^{\circ}$. There was no residual pain and the patient experienced no disability in daily activities, returning to work 4 months after surgery.

Two patients in the control group suffered delayed healing but did not postpone early exercise. The fracture was fully healed in each case, with excellent elbow function. An additional patient in the control group showed signs of heterotopic ossification, but was otherwise asymptomatic.

\section{Discussion}

Radial head fracture accounts for one-third of elbow joint fractures. The principal cause of fracture is high energy impact transmitted from the hand and wrist during a fall (11). This occurs more commonly in energetic sports and hard physical labor. The mean age of affected patients is 45 years (12).

Treatment options for radial head fracture depend on classification, degree of soft tissue damage, dislocation and number of fragments. Isolated nondisplaced fractures, or those with displacement of less than $2 \mathrm{~mm}$ and without mechanical obstruction can be treated by immobilization. Comminuted fractures or those that are simple with displacement of greater than $2 \mathrm{~mm}$ are usually treated surgically(1). Options include open reduction and internal fixation, or radial head excision and arthroplasty. Radial head partial fracture or comminuted fracture having fewer than 3 fragments can be fixed with screws and plates(4). Severely comminuted fractures are almost impossible to fix with plates and screws, and cause a higher rate of failure of fixation, nonunion and osteonecrosis (13). This type of fracture is defined as "unsalvageable" or "unrepairable" radial head fractures $(6,14)$ and are usually treated by radial head resection or arthroplasty.

Deficiency in the radial head will lead to a series of complications such as valgus instability, radius proximal migration with consequent wrist pain, posterolateral rotatory instability and elbow joint dislocation. because the radial head is a secondary stabilizer of the elbow and forearm $(3,6,15,16)$. Therefore, resection of the radial head is now rarely performed and only if the patient is of advanced age and has low functional requirements.

With improvements in radial head prostheses, radial head arthroplasty has become a feasible option for treatment of comminuted radial head fractures (5). Compared with radial head resection, radial head replacement can significantly improve the stability of the elbow joint (5). If the fracture is combined with collateral ligament disruption, elbow joint dislocation, "terrible triad" injuries or Essex-Lopresti injuries, radial head replacement can provide up to $75 \%$ of valgus stability (17). Radial head replacement can significantly shorten the duration of surgery compared with ORIF. This advantage is especially important 
when the fracture is combined with dislocation and soft tissue rupture that requires repair during surgery. Radial head replacement appears to have fewer complications than ORIF in comminuted fracture (18).

Conversely, radial head replacement also suffers characteristic complications. The reliability of prostheses remains controversial. Periprosthetic stem lucency is common during long-term follow-up (9). The majority of lucency is asymptomatic, but some develop into stem loosening combined with varying degrees of pain. Signs of ulnohumeral arthritis in radiographs is found in $38 \%$ of patients 8 to 12 years after arthroplasty. Capitellum resorption is also not difficult to identify(19). Depending on the design of prosthesis, the total survival rate after $8-12$ years varies from $0-24 \%(8,19-21)$. Longer periods of observation are required.

Considering the uncertain long-term outcome of arthroplasty, radial head replacement should be used cautiously on patients under 50 years of age. Every effort should be made to preserve the radial head prior to resection or replacement in patients under 30 years of age. In addition, due to religious beliefs and cultural considerations, it is occasionally difficult to persuade the patient to undergo radial head resection or replacement.

Absorbable pins provide an approach to conduct ORIF of radial head fractures which cannot be fixed with metallic plates and screws. Compared with traditional screws and plates, polylactide pins have a number of unique advantages when treating severely comminuted radial head fractures. Smaller diameters $(1.5 \mathrm{~mm})$ allows fixation of each fragment with multiple pins from different directions. Combined with an "on-table" construction technique, the surgeon can fix a fracture with more than 4 fragments into a "ferroconcrete" structure. In our experience, this technique exhibits high error tolerance capability. In extremely conditions, fractures that have failed to be fixed with screws and plates still can be fixed with polylactide pins, even have $2.5 \mathrm{~mm}$ drill holes on the fragments (Fig. 5). This "ferroconcrete"-like radial head has superior robustness which can tolerate the most drastic reduction manipulation, which the screw and plate technique cannot. In addition, polylactide pins are considerably easier to handle than screws and plates. The surgeon only needs to fix the fracture with as many k-wires as required, which are then replaced with polylactide pins one by one. For screws and plates, the k-wires block the insertion of the screws such that the number and direction of k-wires is restricted, causing in the temporary fixation to be unstable.

In the present study, the duration of surgery and blood loss in both groups was not statistically different. Considering that fractures of the experimental group are clearly more comminuted than the control group (fragment numbers: 4 (SD: 0.6 ) and 3 (SD: 0.3 ), respectively; $p<0.0001$ ), polylactide pins can also shorten the duration of surgery and reduce blood loss. Polylactide pins can easily be thermally cut into any length and placed under cortical bone and cartilage. This completely avoids the risk of joint obstruction and soft tissue irritation. Conversely, metallic screws must be sunk under the cartilage which risks over-compression (Fig. 6) and secondary fractures. Plates must be placed at a "safe-zone" on the radial head which restrict positioning and direction of screw placement (10). 
A number of studies have already compared the outcome of polylactide pins with metallic fixation for the

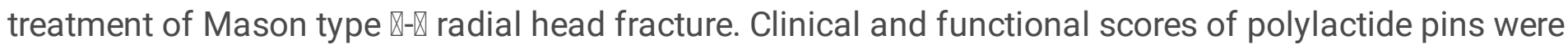
found to be as effective as metallic fixation $(22,23)$. However, the majority of samples in these studies were non-comminuted or only slightly comminuted fractures. Researchers have seldom used polylactide pins to treat "unsalvageable" radial head fractures.

The present study aimed to compare the feasibility of treating severely comminuted radial head fractures using polylactide pins with metallic fixation. In the department of orthopedic of University-town Hospital of Chongqing Medical University, polylactide pins were used to treat radial head fractures with more than 4 fragments. Therefore, the injuries of patients who underwent polylactide pin fixation were more serious than those who received screw and plate fixation. A number of patients also suffered from a combination of injuries such as elbow joint dislocation, "terrible triad" injuries and collateral ligament rupture. Radial head fractures with significant instability of the elbow joint endured considerably worse outcomes than simple fractures $(1,3,14)$. In order to eliminate this factor, fractures in which dislocation, "terrible triad" injuries, coronoid fractures or collateral ligament rupture had occurred were excluded. It is clear that once patients with joint instability had been excluded, there was no statistical difference in long-term function between the experimental and control group. The range of motion of the two groups was almost the same. The pronation angle of the control group appeared to be larger than the experimental group, but not statistically so.

Two to 3 patients in each group suffered complications, but there is no evidence that the complication rate of one group was greater than the other. No complications caused disability and patients were satisfied with the outcome.

Because of the limitations of metallic implants, fractures fixed with polylactide pins are more comminuted than those fixed with metallic implants. This factor affected the consistency of the samples. But since outcomes of the experimental group were similar to those of the control group, despite having more severe comminution, the conclusions remain valid. On the other hand, the number of samples in the study was small. This is in part because a large number of patients with elbow instability were excluded. In addition, follow up periods were not sufficiently long, and so long-term outcomes of this technique are unknown. We plan to add additional samples into the study and follow-up the patients for a longer period. Finally, since arthroplasty is the most commonly used technique to treat severely comminuted radial head fracture, it would be more meaningful to compare polylactide pins with radial head replacement

\section{Conclusions}

In summary, polylactide pins can fix "unsalvageable" radial head fractures which metallic implants cannot. When there are no combined injuries besides radial head fracture, the final outcome of polylactide fixation is as effective as metallic devices, even if the fracture is more comminuted than the 
latter. This provides an additional option other than radial head resection or arthroplasty, which is significant for young patients.

\section{Abbreviations}

DRUJ

distal radioulnar joint; ORIF:open reduction and internal fixation; MEPI:Mayo Elbow Performance Index; VAS:visual analogue scale; DASH:Disabilities of the Arm, Shoulder and Hand out come measure; NSAID:non-steroidal anti-inflammatory drugs; ROM:range of motion

\section{Declarations}

\section{Ethics approval and consent to participate}

The study followed the Helsinki declaration and Nuremberg code and approved by the ethics committee of Chong Qing Medical University. All the data was collected by the responsible physician with the patient consent.

\section{Consent for publication}

Not applicable.

\section{Availability of data and materials}

All data generated or analyzed during this study are included in this published article. The more information and extra data of individual participator are available from the corresponding author on reasonable request.

\section{Competing interests}

The authors declare that they have no competing interests.

\section{Funding}

The study received no funding from any organizations.

\section{Authors' contributions}

$\mathrm{RL}, \mathrm{CY}$ and FG: collected the data, $\mathrm{RL}$ and $\mathrm{FG}$ analyzed the data, $\mathrm{LG}$ and $\mathrm{XY}$ : provide guidance and direction in the study. All of the authors participate in the planning of this study. And RL write the manuscript.

\section{Acknowledgements}

Not applicable 


\section{References}

1. Ring D, Quintero J, Jupiter JB. Open reduction and internal fixation of fractures of the radial head. JBJS. 2002;84(10):1811-5.

2. Herbertsson P, Josefsson PO, Hasserius R, Besjakov J, Nyqvist F, Karlsson MK. Fractures of the radial head and neck treated with radial head excision. JBJS. 2004;86(9):1925-30.

3. Geel CW, Palmer AK. Radial head fractures and their effect on the distal radioulnar joint. A rationale for treatment. Clinical orthopaedics and related research. 1992(275):79-84.

4. Zarattini G, Galli S, Marchese M, Mascio LD, Pazzaglia UE. The Surgical Treatment of Isolated Mason Type 2 Fractures of the Radial Head in Adults: Comparison Between Radial Head Resection and Open Reduction and Internal Fixation. Journal of Orthopaedic Trauma. 2012;26(4):229-35.

5. Heijink A, Kodde IF, Mulder PGH, Veltman ES, Kaas L, van den Bekerom MPJ, et al. Radial Head Arthroplasty: A Systematic Review. JBJS Reviews. 2016;4(10).

6. Catellani F, De Caro F, De Biase CF, Perrino VR, Usai L, Triolo V, et al. Radial head resection versus arthroplasty in unrepairable comminuted fractures Mason type III and type IV: a systematic review. BioMed research international. 2018;2018.

7. Hartzler RU, Morrey BF, Steinmann SP, Llusa-Perez M, Sanchez-Sotelo J. Radial Head Reconstruction in Elbow Fracture-Dislocation: Monopolar or Bipolar Prosthesis? Clinical Orthopaedics and Related Research ${ }^{\circledR} .2014 ; 472(7): 2144-50$.

8. Flinkkilä T, Kaisto T, Sirniö K, Hyvönen P, Leppilahti J. Short-to mid-term results of metallic press-fit radial head arthroplasty in unstable injuries of the elbow. The Journal of bone and joint surgery British volume. 2012;94(6):805-10.

9. Burkhart KJ, Mattyasovszky SG, Runkel M, Schwarz C, Küchle R, Hessmann MH, et al. Mid- to longterm results after bipolar radial head arthroplasty. Journal of Shoulder and Elbow Surgery. 2010;19(7):965-72.

10. Caputo AE, Mazzocca AD, Santoro VM. The nonarticulating portion of the radial head: Anatomic and clinical correlations for internal fixation. The Journal of Hand Surgery. 1998;23(6):1082-90.

11. Tejwani NC, Mehta H. Fractures of the radial head and neck: current concepts in management. JAAOS-Journal of the American Academy of Orthopaedic Surgeons. 2007;15(7):380-7.

12. Rosenblatt Y, Athwal GS, Faber KJ. Current recommendations for the treatment of radial head fractures. Orthopedic Clinics of North America. 2008;39(2):173-85.

13. Ruan H-J, Fan C-Y, Liu J-J, Zeng B-f. A comparative study of internal fixation and prosthesis replacement for radial head fractures of Mason type III. International Orthopaedics. 2009;33(1):24953.

14. Rodriguez-Merchan E. Controversies on the treatment of irreducible elbow dislocations with an associated nonsalvageable radial head fracture. Journal of orthopaedic trauma. 1995;9(4):341-4.

15. Schneeberger AG, Sadowski MM, Jacob HA. Coronoid process and radial head as posterolateral rotatory stabilizers of the elbow. JBJS. 2004;86(5):975-82. 
16. Hall JA, McKee MD. Posterolateral rotatory instability of the elbow following radial head resection. JBJS. 2005;87(7):1571-9.

17. Ahmed I, Mistry J. The management of acute and chronic elbow instability. Orthopedic Clinics. 2015;46(2):271-80.

18. Li N, Chen S. Open reduction and internal-fixation versus radial head replacement in treatment of Mason type III radial head fractures. European Journal of Orthopaedic Surgery \& Traumatology. 2014;24(6):851-5.

19. Marsh JP, Grewal R, Faber KJ, Drosdowech DS, Athwal GS, King GJ. Radial head fractures treated with modular metallic radial head replacement: outcomes at a mean follow-up of eight years. JBJS. 2016;98(7):527-35.

20. Popovic N, Lemaire R, Georis P, Gillet P. Midterm results with a bipolar radial head prosthesis: radiographic evidence of loosening at the bone-cement interface. JBJS. 2007;89(11):2469-76.

21. Harrington IJ, Sekyi-Otu A, Barrington TW, Evans D, Tuli V. The functional outcome with metallic radial head implants in the treatment of unstable elbow fractures: a long-term review. Journal of Trauma and Acute Care Surgery. 2001;50(1):46-52.

22. Su Y, Xie Y, Qin J, Wang Z, Cai W, Nan G. Internal Fixation With Absorbable Rods for the Treatment of Displaced Radial Neck Fractures in Children. Journal of Pediatric Orthopaedics. 2016;36(8):797-802.

23. Tarallo L, Mugnai R, Rocchi M, Capra F, Catani F. Comparison between absorbable pins and miniscrew fixations for the treatment of radial head fractures Mason type II-III. BMC Musculoskeletal Disorders. 2018;19(1):94.

\section{Figures}
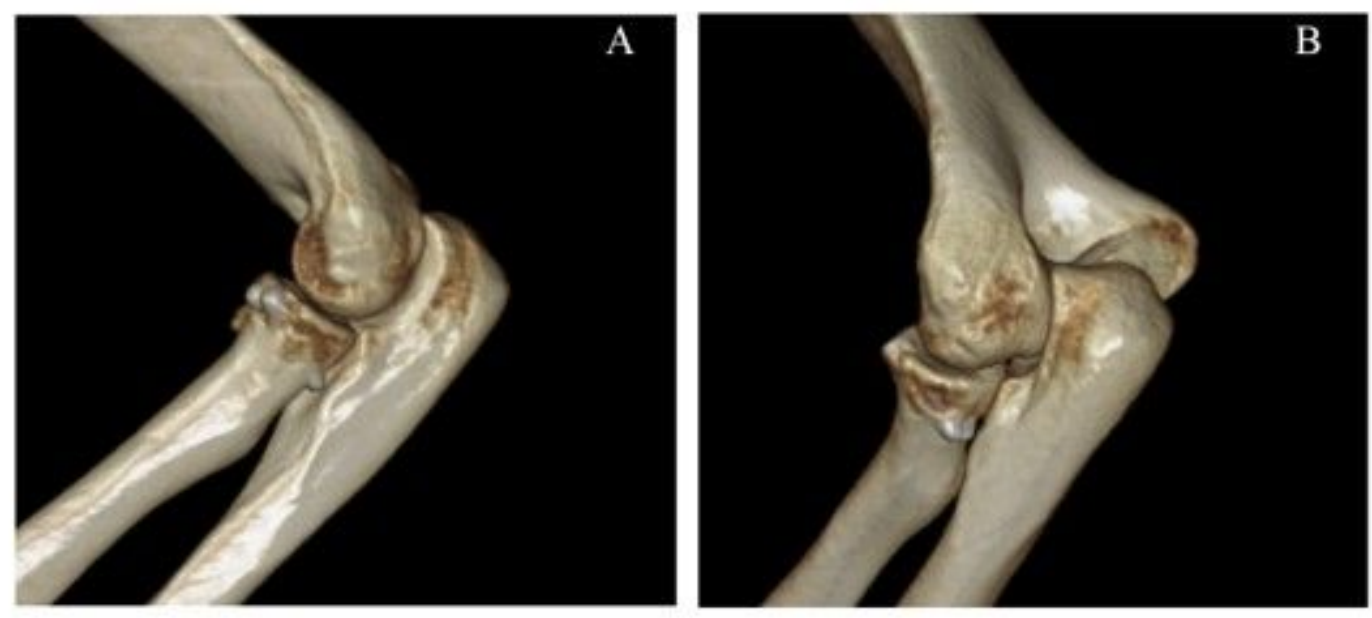

\section{Figure 1}

inclusion criteria 


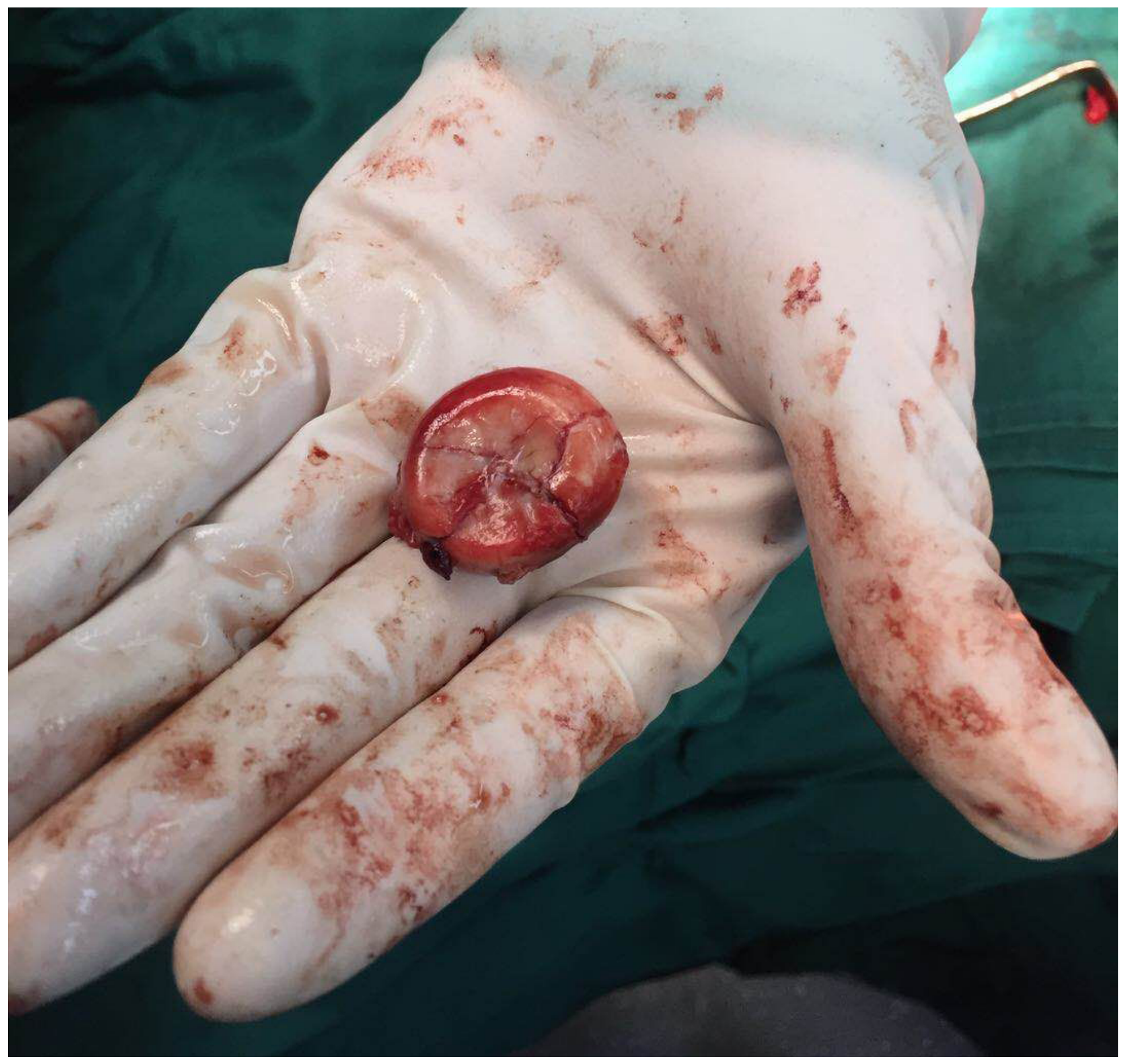

\section{Figure 2}

the severely comminuted radial head was reconstructed in vitro and fixed with polylactide pins 

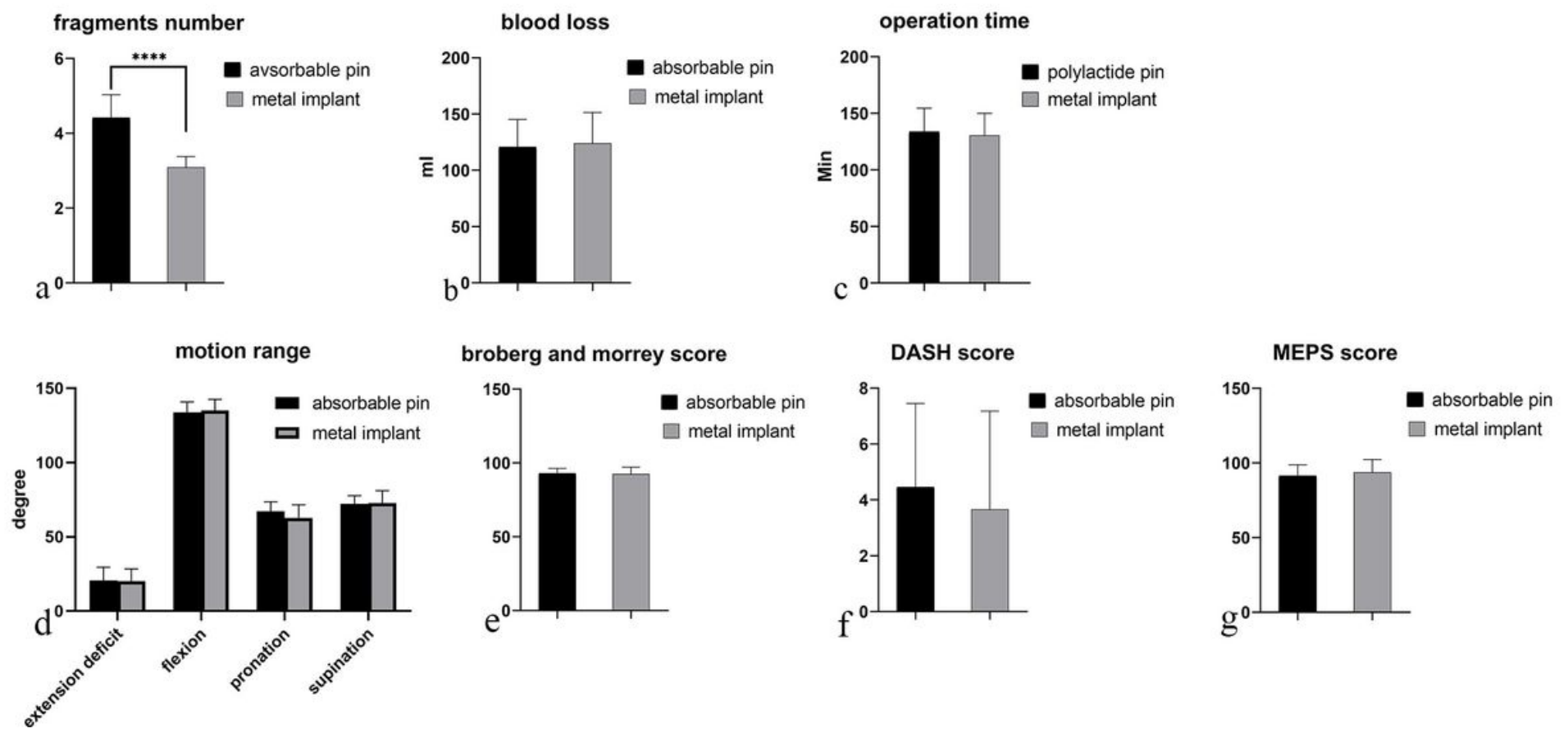

Figure 3

the compare between experiment group and control group. (a)the fragment number; (b)Blood loss in operation; (c)operation time; (d)motion range; (e)broberg and morrey score; (f)DASH score; (g)MEPS score 

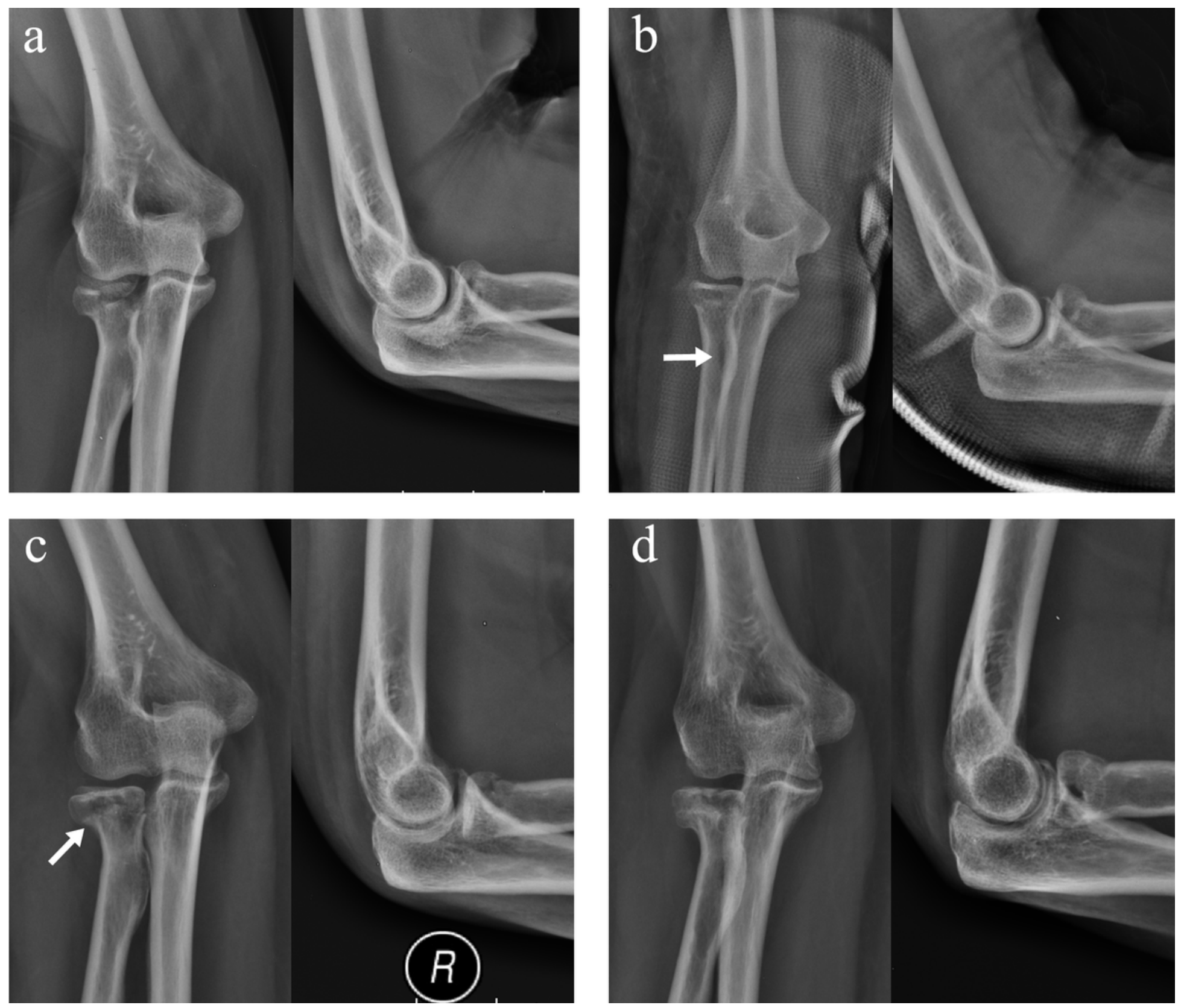

\section{Figure 4}

(a)x-rays before surgery. (b)2 days after surgery, from the overlapping of ulna and radius(white arrow) we can see that the forearm of patient is in a slight pronation position. (c) 4 weeks after surgery, the radial head look like have a ulnar side migration. But it is hard to say this is a pre-existing malreduction or a fixation loosening. (d) the migration do not progress. The fracture fully healed at 6 month after surgery. Xrays show slightly bone absorption of radial head and the gap between radial head and capitellum was slightly broadened. There is no instability exist and the function is good. 
a

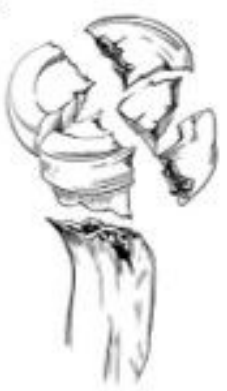

b

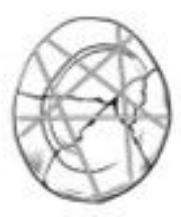

c

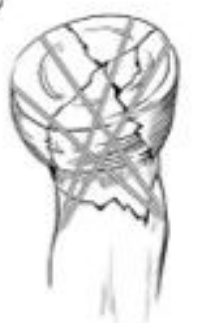

d

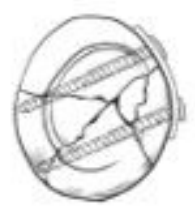

\section{Figure 5}

(a) the pattern of "unsalvageable" fracture. (b) on-table reduction of radial head and fixed with polylactide pin, multiple direction of polylactide pin formed a "ferroconcrete" structure. (c) the reconstructed radial head was fixed on the neck with multiple polylactide pins from different directions. (d) the nonarticular zone restrict the position of screw, makes it hard to fix all the fragments with two parallel screw. Meantime The comminuted radial head lack the bone substance beneath the cartilage, which is more like a cartilage cap. If the screw can't penetrate 2 layers of cortical of one fragment, the fixation is insecure. 

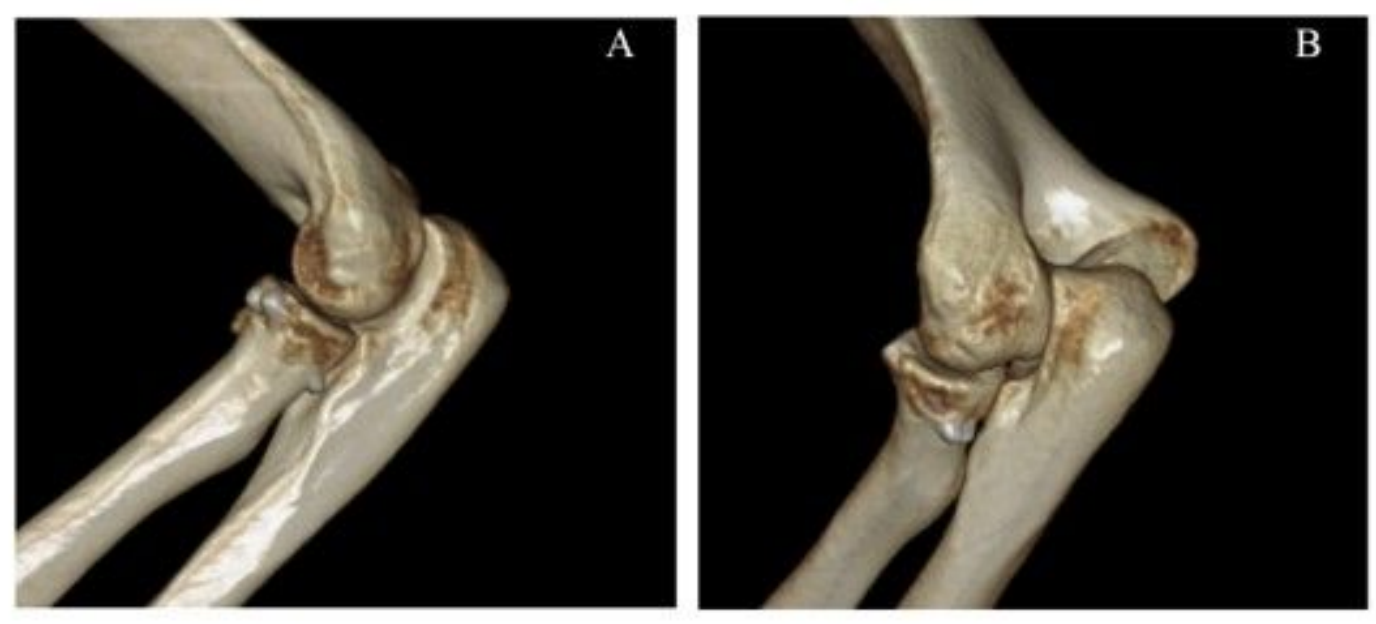

Figure 6

a 65 years old female fixed with two headless compressing screw. The fragment broken join the tightening and was over compressed. The screw tip jut from the opposite cortical. Fortunately, the screw did not block the rotation of proximal radioulnar joint. 